\title{
Study on Curriculum Reform of "Analytical Chemistry" for Metropolitan Agricultural and Forestry Colleges
}

\author{
Sichun Yuan ${ }^{\mathrm{a}}$, Qian $\mathrm{Luo}^{\mathrm{b} *}$, Yunle $\mathrm{Li}^{\mathrm{c}}$, Xing $\mathrm{Ge}^{\mathrm{d}}$ \\ Basic Course Department \\ Beijing University of Agriculture \\ Beijing, China \\ aysc2007@ sina.com, ${ }^{b}$ kongqfd@ sina.com, ${ }^{c}$ liyunle@ sina.com, ${ }^{d}$ gexing1226@gmail.com \\ * Denotes corresponding author
}

\begin{abstract}
Analytical Chemistry is science that study of the chemical composition and structure information, an important branch of Chemistry, also one of important necessary technologies of industrial development and research for farming, animal husbandry, biotechnology, plant breeding, environmental protection, food industry and etc. "Analytical Chemistry" is an important foundation courses in agricultural and forestry colleges. It is highly related to whether highquality, comprehensive, applied talents can be cultivated, which is also special needs for urban agriculture colleges personnel training, that how to improve the quality of "Analytical Chemistry" teaching, while enabling students to master their professional basic theoretical knowledge and basic operating skills. In our school, "Analytical Chemistry" course is a required basic course for bio-engineering, biotechnology, plant production, agricultural resources and environment, animal science, animal medicine, forestry, landscape architecture, food engineering and food safety and etc.
\end{abstract}

Keywords-analytical chemistry; curriculum reform; higher education; agricultural and forestry institutions

\section{INTRODUCTION}

Construction of higher educational institutions is the foundation works to achieve courses teaching plan, training objectives, also to ensure training quality. "Analytical Chemistry" makes no exception of being an important part in the construction of agricultural and forestry colleges' courses.

Therefore, we, curriculum unit "Analytical Chemistry", during tutorial, need to focus on teaching reform and research, pay close attention to the construction of teaching materials and teaching methods and means of reform. Also, it achieved better results of course curriculum construction for "Analytical Chemistry", by strengthening the sense of quality, emphasizing importance of experimental teaching in the Analytical Chemistry.

\section{DEFINE GUIDING IDEOLOGY AND OBJECTIVES OF THE COURSE CONSTRUCTION}

After a very long period of development, modern analytical chemistry have undergone a tremendous change in both disciplinary foundation and technical means to form as today's analytical chemistry, the one drawing on new scientific achievements of contemporary chemistry, physics, mathematics, electronics and computer, with its own new methods and new technology of characterization measurements. It is a modern analytical science that solves practical problems during production of construction and scientific research by obtaining useful information from data analysis. The basis of theoretical and experimental techniques of analytical chemistry is necessary, not only for professionals in the analytical chemistry research and development of the life sciences, environmental science, agricultural science, food science and many other disciplines cannot be considered apart from the progress and development of the principles and techniques of analytical chemistry. Obviously, analytical chemistry has a strong practical usage, while it has strict and systematic theory; it is the close combination of theory and practical disciplines. Learning analytical chemistry is helpful to train the students' rigorous scientific attitude and pragmatic style, to guide students to initially grasp the skills and preliminary scientific research with the overall quality of scientific research. Construction of analytical chemistry courses is considered great significance related to the cultivation.

Clearly defined "Analytical Chemistry" course construction guiding ideology and goals plays a vital role to the curriculum construction. "Analytical Chemistry" guiding ideology and objectives of the course construction are as follows: stick with the spirit of the guiding ideology of "Three-oriented" education, from metropolitan agricultural and forestry colleges' reality, to meet the general idea of the 21 st century teaching contents and curriculum reform basis, in accordance with the "thick foundation, wide caliber, strong capacity, high-quality, wide adaptation" of applied training model for higher educational institutions, for the purpose of comprehensive personnel training quality and ability, for the purpose of the course overall optimization, proceed all-round, integration of reform and construction, to build the new curriculum system.

\section{STRENGTHENING THE TEACHING STAFF TRAINING}

The building of the faculty is an important part of the construction of the course, also the basis of the teaching. Teachers of "Analytical Chemistry" teaching team, in their teaching positions, serve conscientiously, hardworking, and always take their life-long pursuit of the career as being an 
excellent teacher of the people, always remember being teachers, teaching and educating. They have been a noble character, rigorous style and profound knowledge to teach students. Guiding by modern educational theory and modern teaching concept, keeping reformation, innovating teaching mode, focusing on the cultivation of students' abilities, teachers made significant effort. Teachers in the long-term teaching work, has accumulated a wealth of experience in teaching.

In order to make it more adaptive to the needs of the personnel training and teaching of analytical chemistry courses, "Analytical Chemistry" course group developed the training for teachers in details and in practice. There are plans for classroom teachers, for continuing education, advanced studies, to further improve the level of teaching and research capacity of the teachers. The group of "Analytical Chemistry" teachers is a united and progressive collective. On the basis of existing teachers, we have to further improve the teaching ability and level of scientific research for this particular group of teachers. When the conditions are right, sending young teachers abroad for further study could raise quality and ability of young teachers, in particular, the ability of bilingual teaching. Teachers of analytical chemistry course group got plenty of exercise in the practice of teaching and research, then enrich content of teaching with the achievements of teaching and research.

\section{EQUAL IMPORTANCE OF TEACHING AND SCIENTIFIC RESEARCH}

According to the characteristics of the agricultural and forestry colleges, on the basis of the existing curriculum reformation, reform on teaching content and teaching methods. Further, revise and improve "Analytical Chemistry" course syllabus and the syllabus of the analytical chemistry experiment. Strengthen the construction of teaching materials, and gradually realize the multi-layer and multi-dimension of teaching materials. To form an integrated curriculum system, it can be achieved by consummating multimedia courseware and matching exercises library.

The teaching group of analytical chemistry course closely integrates teaching and research. The teachers are not only a higher level of teaching and scientific research, but also capable of producing higher levels of multimedia courseware and great teaching effectiveness. They have chaired, involved in a number of various levels of teaching and research projects and scientific research projects; published dozens of papers in various journals at within the country and overseas. They also have been editor, deputy editor and have supervised many textbooks.

\section{IMPROVE TEACHING METHODS AND MEANS}

With the development of science and technology, the teaching of analytical chemistry experienced from period of teachers taught mainly using chalk and blackboard, with a gradual transition to a multi-faceted space teaching which making use of multimedia courseware, teaching video clips, slides, and hand-made teaching aids. Accordingly, some reform update of teaching content has been made, to let classroom atmosphere livelier, and effectively improve the quality of teaching. Back to the year of 2000, our school's analytical chemistry curriculum group focused primarily on reform of teaching infrastructure and teaching methods. Reforms, since the year of 2006, are done to the teaching systems, causing teaching content had according adjustments. Taking college personnel training requirements as a starting point, the reform experience of domestic key universities and the actual situation of our school as the reference, a corresponding adjustment of the analytical chemistry syllabus and experimental outline has been made. Related textbooks are written (theoretical textbook and the experimental textbook) as well as learning guidebooks, selfmade electronic courseware, developed innovative experiments, established related test database, along with various aspects of the course content and teaching has reformed. Instruction methods are mainly consisted with lectures, with the use of electronic courseware, teaching video clips, and other media space pedagogy. It makes classroom teaching vivid; also facilitates the students' understanding of the course content, and increase the amount of information taught received, in general, achieved better teaching effectiveness.

Teaching methods - (1) Teachers' way of teaching: impart knowledge with training scientific way of thinking, and cultivate the students' ability to analyze problems. (2) Participatory discussion: outline for the discussion provided by teachers, then students summarize points of learning content. Organizing lecture by questioning approach, learning through cooperation and research, it is to cultivate students' ability of summarizing analysis. (3) Students' own way of learning: teacher provides training topics and information; students independently complete analytical chemistry experiment design. Cultivate students' innovative research capabilities, and improve the science and culture quality of the students.

Teaching measures - Multimedia Educational Technology: by using Photoshop and Flash software, make the images and animations of the chemistry reaction, experimental procedures, internal structure of instrument, and measurement principle, to reproduce the process which is difficult to be observed and to be achieved; by using PowerPoint software to create multimedia courseware, increase the amount of information of within the lecture time, also it can be updated easily with the information of analytical chemistry development. It is illustrations, vivid, interactive, online available courseware, to facilitate students to preview, self-study and review.

\section{EXPERIMENT TEACHING}

Experiment teaching section of analytical chemistry course is the analytical chemistry experiment. Strengthening laboratory construction and construction of teaching basic conditions, is guarantee to full show and innovate students' theoretical knowledge learned in the classroom in the laboratory, also basis for cultivating scientific spirit and spirit 
of innovation. That is why we need to provide excellent laboratory environment and conditions to improve the abilities of students and their innovative thinking

From the perspective of educating people, to develop students' ability to innovate has been the purpose throughout experiment teaching section of analytical chemistry course. Integrated with contributions to the progress of human society and civilization made by chemistry, the goal is to strengthen the students' own qualities that needed to become a qualified 21st Century application-oriented talents, by educating students to put their own ideals and the country's prosperity and development in close connection, with students patriotism quality and a sense of national pride. Meanwhile, from various levels of experimental courses, students will get a comprehensive, standardized, rigorous training to grasp, understand, realize how to think and solve problems, and to gradually establish a rigorous scientific attitude and ability to obtain knowledge, master knowledge, and to apply knowledge.

\section{THE NETWORK AND MULTIMEDIA TEACHING ENVIRONMENT IS UNDER CONSTRUCTION}

Because of the new technologies applied to higher education, students can easily get variety of educational information. "Analytical Chemistry" teaching is in such an environment, through modern education technology and teaching methods, to achieve multimedia classroom teaching, and to gradually implement all the sections such as assignments submission, grading, Q\&A, teaching evaluation available online. This will need to improve the existing multimedia-teaching environment, build a network teaching environment. There is still a lot of work to do: (1) Recording video through lectures. (2) Produce guidance videos for some experiments. (3) Upload teaching resources to the Internet. The syllabus, electronic lesson plans, multimedia courseware, full lecture video, experimental guidance, quiz library and etc. should all be uploaded to the Internet, and later, gradually improve the online test session.

\section{BUILD A MORE SCIENTIFIC AND STANDARDIZED ASSESSMENT SYSTEM}

Evaluation of the quality of teaching is one of the most important elements of the curriculum construction; it needs a scientific, complete, comprehensive assessment system. It is necessary that to use variety of examinations and assessment, to scientifically, accurately and comprehensively examine basic capabilities, comprehensive knowledge, abilities and qualities of students.

Via course construction, it is a perfect time to reform course examination and assessment system and methodology, with building and perfecting exercises library, test bank, online experimental test library system and etc at the same time. To improve the course examination and assessment system and lay the foundation for the next step textbook revision, we should research on course evaluation system, evaluation methods and related exercises library, library usage and other problems, and then gather feedback for "Analytical Chemistry" course construction.

After a long struggle, "Analytical Chemistry" course construction has made certain achievements, but also need to further implement more construction of the course, to solve existing problems. We will further strengthen the building of analytical chemistry courses, to make it a very important course to urban agriculture talent knowledge systems with features of practical characteristics and skills development.

\section{ACKNOWLEDGMENT}

We would like to thank Office of Academic Affairs, Beijing University of Agriculture, for their support of funding the education and teaching reform project.

\section{REFERENCES}

[1] Zheng Xiuwen, Yang Mingmin. Analytical Chemistry courses teaching reform. The Chinese Agricultural Education (bimonthly) February 2003: p36-37 (In Chinese)

[2] Lin Weili, Wu Shenjiang. Exploration of Analytical Chemistry teaching method. Era education. 2009 February: p93 (In Chinese)

[3] Wang YingYing. Exploration of improving the effect of Analytical Chemistry Teaching. EDUCATION INNOVATION GUIDE .2009 19: p53 (In Chinese)

[4] Yang Dongwei, Shi Changhua. Reform analytical chemistry experimental teaching method training creative ability. Laboratory science. 3 June 2009: p35-36 (In Chinese)

[5] Liang Xinyuan, Cai Zhuo, Huang Xiaofeng. Talking about the practice and experience of analytical chemistry experiment teaching reform in the agriculture and forestry. Guangxi University (Philosophy and Social Sciences) .2009 April 31 (Suppl.): p106-108 (In Chinese) 